\title{
BMJ Open Maternal characteristics associated with gestational weight gain in France: a population-based, nationally representative study
}

\author{
Melissa Amyx (D) , ${ }^{1}$ Jennifer Zeitlin, ${ }^{1}$ Monika Hermann, ${ }^{1}$ Katia Castetbon, ${ }^{2}$ \\ Béatrice Blondel, ${ }^{1}$ Camille Le Ray ${ }^{1,3}$
}

To cite: Amyx M, Zeitlin J, Hermann M, et al. Maternal characteristics associated with gestational weight gain in France: a population-based, nationally representative study. BMJ Open 2021;11:e049497. doi:10.1136/ bmjopen-2021-049497

- Prepublication history and additional supplemental material for this paper are available online. To view these files, please visit the journal online (http://dx.doi.org/10.1136/ bmjopen-2021-049497).

Received 08 February 2021 Accepted 11 June 2021

\section{Check for updates}

(c) Author(s) (or their employer(s)) 2021. Re-use permitted under CC BY-NC. No commercial re-use. See rights and permissions. Published by BMJ.

${ }^{1}$ Obstetrical, Perinatal and Pediatric Epidemiology Research Team (EPOPé), Center for Research on Epidemiology and Statistics Sorbonne Paris Cité (CRESS), University of Paris, INSERM UMR 1153, Paris, France

${ }^{2}$ Epidemiology, Biostatistics and Clinical Research Research Center, ULB School of Public Health, Brussels, Belgium

${ }^{3}$ Cochin Hospital Port Royal, Port Royal Maternity, Department of Obstetrics, University of Paris, APHP, Paris, France

Correspondence to Dr Melissa Amyx; melissa.amyx@inserm.fr

\section{ABSTRACT}

Objectives To provide nationally representative estimates of gestational weight gain (GWG) and identify maternal characteristics associated with inadequate GWG in France.

Design A population-based study using data from the French National Perinatal Survey: 2010 and 2016.

Setting All maternity units in metropolitan, mainland France ( $n=535$ in 2010; $n=493$ in 2016).

Participants Singleton live births with GWG data ( $N=24$ 850).

Primary outcome measures GWG was calculated as end of pregnancy minus pre-pregnancy weight $(\mathrm{kg})$ and categorised as 'insufficient', 'adequate', or 'excessive' using 2009 Institute of Medicine thresholds. Classification accounted for pre-pregnancy body mass index (BMI) (kg/ $\mathrm{m}^{2}$; underweight $(<18.5)$, normal weight (18.5-24.9), overweight (25-29.9), obese ( $\geq 30)$ ) and gestational age at birth. We estimated average GWG and the percentage of women in each GWG category. Polytomous logistic regression identified characteristics associated with GWG adequacy.

Results Average GWG was 13.0 kg (SD 5.6), with $26.8 \%$ of women gaining insufficiently, $37.0 \%$ adequately and $36.1 \%$ excessively. Among other factors, insufficient GWG was associated with underweight (vs normal weight; adjusted $\mathrm{OR}(\mathrm{aOR}) 1.4,95 \% \mathrm{Cl} 1.2$ to 1.5 ) and obese (aOR 1.5, 95\% Cl 1.4 to 1.7) BMl. Excessive GWG was associated with overweight (aOR 2.8, 95\% Cl 2.6 to 3.1) and obese BMI (aOR 3.3, 95\% Cl 2.9 to 3.6). Examining obesity classes separately, odds of insufficient GWG increased from obesity class I to III, while odds of excessive GWG decreased from obesity class I to III. Primiparity (insufficient: aOR 0.9, 95\% Cl 0.9 to 1.0; excessive: a0R 1.2, 95\% $\mathrm{Cl} 1.2$ to 1.3), maternal characteristics indicative of lower socioeconomic status, and continuing or quitting smoking during pregnancy were also associated with inadequate GWG.

Conclusions In France, insufficient and excessive GWG are common. For optimal outcomes, clinician education, with special attention to the needs of higher risk/ vulnerable groups, is needed to ensure all women receive appropriate advice for recommended GWG.
Strengths and limitations of this study

- This is the first nationally representative study of risk factors for gestational weight gain (GWG) in France.

- The French National Perinatal Survey includes all maternity units in metropolitan, mainland France.

- Specially trained study midwives collected extensive, rigorous data through maternal interview and chart abstraction.

- The definition of GWG adequacy incorporated length of gestation, limiting potential bias due to the correlation between GWG and length of gestation.

- Some data (including pre-pregnancy body mass index and GWG) were self-reported and collected retrospectively, which could result in measurement error.

\section{INTRODUCTION}

Due to demographic and lifestyle changes, women are entering pregnancy with a higher body mass index (BMI) and gaining excessive pregnancy weight. ${ }^{1-4}$ These trends are concerning as both healthy $\mathrm{BMI}^{15}$ and adequate gestational weight gain (GWG) are important for optimal fetal growth and pregnancy/birth outcomes. Specifically, excessive GWG is associated with caesarean birth, ${ }^{6} 7$ postpartum weight retention/ obesity, ${ }^{89}$ increased infant size ${ }^{710}$ and childhood overweight/obesity. ${ }^{11}{ }^{12}$ Conversely, insufficient GWG is associated with decreased infant size ${ }^{71013}$ and preterm birth. ${ }^{7}$ In 2009, the USA's Institute of Medicine (IOM; now National Academy of Medicine) updated GWG guidelines, stratified by maternal prepregnancy BMI, to improve care for the contemporary obstetric population. ${ }^{1}$ While the current IOM guidelines provide a single recommendation for GWG for all women with obese pre-pregnancy BMI, whether separate guidelines are needed by obesity class is unclear due to insufficient evidence. Further, 
the American College of Obstetricians and Gynecologists determined that evidence is lacking to recommend that women with obese BMI with GWG below the IOM recommendations but with an appropriately growing fetus should be encouraged to increase their GWG. ${ }^{14}$

Because GWG is modifiable and pregnant women interact frequently with healthcare providers, identification of factors associated with total GWG and inadequate GWG (insufficient or excessive) is necessary to target context-specific recommendations for GWG interventions/counselling. In addition to maternal prepregnancy BMI, numerous maternal factors, including sociodemographic characteristics, are potentially associated with GWG. ${ }^{815-27}$ However, evidence gaps exist, as most studies of GWG risk factors were conducted in the USA $^{8161720222425}$ and many had a relatively small sample size $(\mathrm{N}<1000), 1922232627$ used GWG guidelines 816171922 or collected data prior to the 2009 IOM guidelines, ${ }^{15} 1825$ or focused narrowly on specific risk factors. ${ }^{22-26}$ Therefore, additional research on risk factors related to GWG is needed in large, contemporary, diverse populations, specifically in nationally representative populations outside of the USA.

In France, both maternal pre-pregnancy BMI and the prevalence of inadequate GWG are increasing. ${ }^{3} 2829$ While previous French GWG studies evaluated adverse outcomes of $\mathrm{GWG}^{12}{ }^{30-32}$ or reported overviews of the main pregnancy indicators, ${ }^{28}{ }^{29}$ no study has comprehensively assessed GWG risk factors in France. Compared with the USA (where most previous studies on the association between risk factors for GWG were conducted), the French obstetric population differs on key factors related to weight and GWG (eg, lower BMI ${ }^{28} 33$ and higher rates of smoking ${ }^{28}{ }^{34}$ in the French obstetric population) and benefits from the world's highest performing healthcare system based on a WHO study of overall efficiency. ${ }^{35}$ Thus, the risk factors previously identified may not be relevant in France. To build on prior evidence within a more contemporary, robust, nationally representative cohort in a unique location and thereby inform local medical professionals providing care to pregnant women and international researchers evaluating consistency of risk factors across different cultural and organisational settings, our objectives were to provide population-based estimates of average GWG and the percentage of women achieving insufficient, adequate or excessive GWG, and identify maternal characteristics and social factors associated with mean GWG and insufficient and excessive GWG in France.

\section{METHODS}

\section{Study design and population}

We combined data from the $2010^{29}$ and $2016^{28}$ French National Perinatal Surveys (NPSs), which are routine, nationally representative surveys including all live and stillbirths in all maternity units in metropolitan, mainland France ( $\mathrm{n}=535$ in 2010; $\mathrm{n}=493$ in 2016). In each survey, data were collected during 1 week. Data collection, performed by trained study midwives, included a face-toface interview of women prior to hospital discharge (2-3 days following birth) using a standardised questionnaire to obtain information related to sociodemographic characteristics and antenatal care and chart abstraction to obtain information on maternal and neonatal health and delivery.

After combining data from both years, the survey sample included 27828 women ( $\mathrm{n}=14681$ in 2010; $\mathrm{n}=13$ 147 in 2016). We excluded multiple births $(n=221$ in 2010; $\mathrm{n}=234$ in 2016), pregnancy terminations $(\mathrm{n}=53$ in 2010; $\mathrm{n}=52$ in 2016) and stillbirths $(\mathrm{n}=76$ in 2010; $\mathrm{n}=73$ in 2016), which may have distinct GWG patterns. We also excluded women with missing $(n=872$ in $2010 ; n=1392$ in 2016) or implausible GWG, defined as gain $>50 \mathrm{~kg}$ or loss $>30 \mathrm{~kg}^{936}(\mathrm{n}=4$ in 2010; $\mathrm{n}=1$ in 2016). Based on missing/ implausible GWG, $<10 \%$ of women with singleton live births in the NPS were excluded. Our final analysis included 24850 women ( $\mathrm{n}=13455$ in 2010; $\mathrm{n}=11395$ in 2016; figure 1).

\section{GWG variables}

Observed GWG $(\mathrm{kg})$ was calculated based on women's selfreported end of pregnancy minus pre-pregnancy weight. Then, GWG adequacy (insufficient, adequate, excessive) was determined by maternal pre-pregnancy BMI (kg/ $\mathrm{m}^{2}$; using self-reported height and pre-pregnancy weight; underweight $(<18.5)$, normal weight $(18.5-24.9)$, overweight (25-29.9), obese $(\geq 30))^{37}$ and was standardised across gestational ages using a previously described method $^{38}{ }^{39}$ based on the assumptions underlying the 2009 GWG IOM guidelines, as detailed in table 1.

French guidelines for GWG (2007 French National Nutrition and Health Program (Programme National Nutrition et Santé) $)^{40}$ differ from IOM guidelines, recommending GWG of $12 \mathrm{~kg}$ for women with normal prepregnancy BMI, lower GWG (not under $7 \mathrm{~kg}$ ) for women with overweight or obese pre-pregnancy BMI, and higher GWG for women with underweight pre-pregnancy BMI. However, as French guidelines do not provide upper and lower ranges and IOM guidelines establish clear categories of GWG adequacy, are routinely used in clinical practice and research in other countries, and are better known by French clinicians and therefore likely more widely used in clinical practice, we used the IOM guidelines in our analysis.

\section{Covariates}

Maternal characteristics collected by interview prior to hospital discharge used are: pre-pregnancy BMI (defined above; obesity further categorised as obese class I (BMI 30-34.9), II (BMI 35-39.9) and III (BMI $\geq 40)$ ), ${ }^{37}$ parity (primiparous, multiparous), and age (<25, 25-29, 30-34, $\geq 35$ years). Maternal social characteristics included: country/region of birth (France, Europe, Northern Africa, sub-Saharan Africa, other), employment and timing of maternity leave during pregnancy (none; 


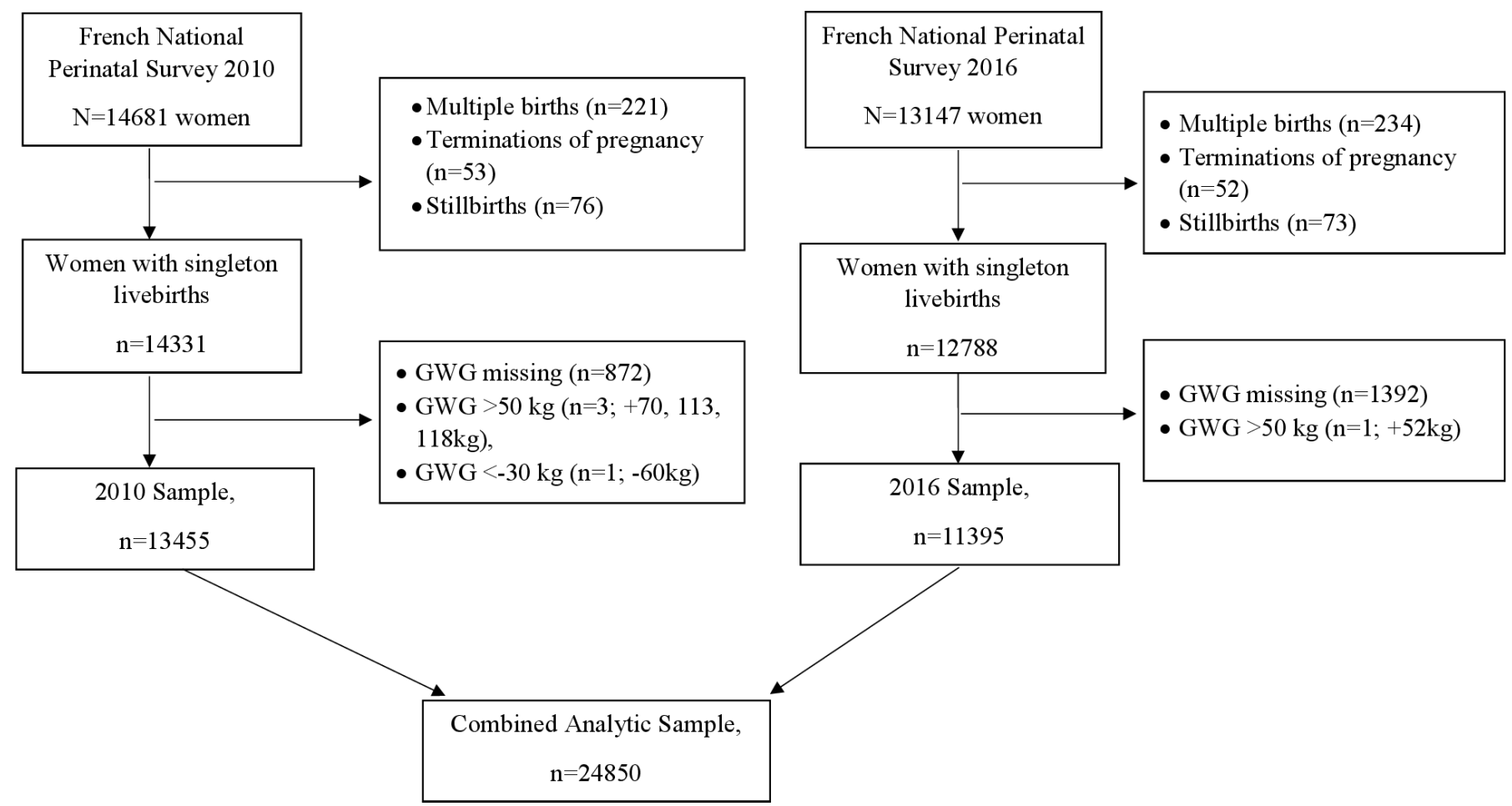

Figure 1 Participant flow chart. GWG, gestational weight gain.

stopped working before $14+0,28+0,32+0$, at/after $32+0$ weeks' gestation, or at an unknown time point), and education ( $<$ high school; high school completed; 1-2, $3-4$, or $5 /$ more years postgraduation). Smoking was evaluated based on smoking prior to pregnancy versus in the third trimester (for each time point: non-smoker/stopped smoking, $<10$ cigarettes per day ( $\mathrm{cig} / \mathrm{d}), \geq 10 \mathrm{cig} / \mathrm{d}$ ), categorised as: non-smoker at both time points; $<10 \mathrm{cig} / \mathrm{d}$, stopped; $\geq 10 \mathrm{cig} / \mathrm{d}$, stopped; $\geq 10 \mathrm{cig} / \mathrm{d}$, reduced to $<10$ $\mathrm{cig} / \mathrm{d} ;<10 \mathrm{cig} / \mathrm{d}$, maintained at $<10 \mathrm{cig} / \mathrm{d} ; \geq 10 \mathrm{cig} / \mathrm{d}$, maintained at $\geq 10 \mathrm{cig} / \mathrm{d}$; increased smoking (combined groups of: non-smoker, increased to $<10 \mathrm{cig} / \mathrm{d}$; nonsmoker, increased to $\geq 10 \mathrm{cig} / \mathrm{d} ;<10 \mathrm{cig} / \mathrm{d}$, increased to $\geq 10 \mathrm{cig} / \mathrm{d}$ ). Social deprivation was based on an index derived within the 2010 NPS based on: receipt of social benefits (household receiving Revenu de Solidarité Active allowance; woman receiving Couverture Maladie Universelle, French social security or not insured), not living in her own accommodation, or not living with a partner. ${ }^{41}$ Insufficient prenatal care was defined as late pregnancy declaration (national health insurance not notified in first 3 completed months and no nuchal translucency

Table 1 GWG adequacy determination using a previously described method, based on IOM guidelines, which incorporates gestational age at delivery*

\begin{tabular}{llllll}
\hline & \multicolumn{2}{l}{$\begin{array}{l}\text { IOM recommendations/assumptions for GWG at } \\
\mathbf{4 0} \text { weeks' gestation }\end{array}$} & $\begin{array}{l}\text { Conversion to proportions of GWG } \\
\text { achieved }\end{array}$ \\
\cline { 2 - 4 } $\begin{array}{l}\text { 1st trimester } \\
\text { GWG } \mathbf{( k g )}\end{array}$ & $\begin{array}{l}\text { Rate of GWG } \\
\mathbf{( k g / w e e k )}\end{array}$ & $\begin{array}{l}\text { Recommended } \\
\text { range } \mathbf{( k g )}\end{array}$ & $\begin{array}{l}\text { Expected GWG } \\
\text { at 40 weeks }\end{array}$ & $\begin{array}{l}\text { Recommended range } \\
\text { of proportion of GWG }\end{array}$ \\
\hline Underweight & 2 & 0.51 & $12.5-18$ & 15.77 & $0.79-1.14$ \\
\hline Normal weight & 2 & 0.42 & $11.5-16$ & 13.34 & $0.86-1.20$ \\
\hline Overweight & 1 & 0.28 & $7.0-11.5$ & 8.56 & $0.81-1.34$ \\
Obese & 0.5 & 0.22 & $5.0-9.0$ & 6.44 & $0.78-1.41$ \\
\hline
\end{tabular}

*Steps to determine GWG adequacy: (1) Expected GWG at 40 weeks computed: recommended first trimester gain+[(GA at

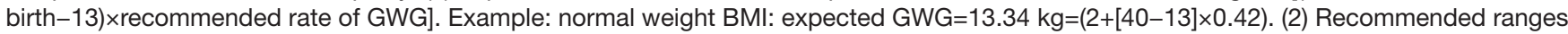
of total GWG for each BMI group converted to ranges of proportions: lower and upper bounds of the IOM recommended range divided by the expected GWG at 40 weeks. Example: normal weight BMI: 0.86-1.20 (11.5/13.34; 16/13.34). (3) For each woman, her individual proportion of recommended GWG achieved determined: observed GWG divided by her expected GWG (using formula from step 1). (4) Individual proportion of recommended GWG achieved compared with ranges of proportions for her BMI group. GWG adequacy classified as: insufficient, below lower bound; adequate, within recommended range; excessive, above upper bound. †BMI $\left(\mathrm{kg} / \mathrm{m}^{2}\right)$ : underweight, <18.5; normal weight, 18.5-24.9; overweight, 25-29.9; obese, $\geq 30$.

BMI, body mass index; GA, gestational age; GWG, gestational weight gain; IOM, Institute of Medicine. 
measurement in first trimester) or insufficient sonograms ( $<2$ if gestational age (GA) at birth $24-33$ weeks; $<3$ if GA at birth 34 weeks or later) or prenatal visits $(<3$ if GA at birth 24-27 weeks; $<4$ if GA at birth 28-31 weeks; $<5$ if GA at birth 32-35 weeks; <6 if GA at birth 36 weeks or later), consistent with French guidelines for low-risk women. ${ }^{42}$ Pre-pregnancy conditions/pregnancy complications, obtained from chart abstraction and used for descriptive purposes, included diabetes in pregnancy (no; diet controlled; insulin controlled) and pre-existing hypertension.

\section{Statistical analysis}

To describe the GWG profile of our cohort, for both survey years combined and individually, mean GWG (with SDs) and prevalence of insufficient, adequate and excessive GWG were reported, overall and by BMI category. The characteristics of included women and women excluded for missing GWG were determined and compared.

Next, the associations between maternal characteristics and GWG and GWG adequacy were evaluated. First, unadjusted linear regression models were used to estimate mean GWG (SD) within levels of maternal characteristics. Then, adjusted linear regression models were used to estimate adjusted mean differences in GWG (and 95\% CIs) between categories of maternal characteristics, with a mean GWG difference of $>1 \mathrm{~kg}$ considered clinically significant. Similarly, adjusted polytomous logistic regression models were used to examine the association between maternal characteristics and GWG adequacy (adjusted OR, 95\% CI calculated). Based on covariates previously associated with GWG, adjusted regression models adjusted for all maternal characteristics listed previously as covariates (BMI obesity classes combined), as well as maternal height (metres), GA at birth (days; linear models only, as GA at birth accounted for in definition of GWG adequacy), and survey year. The pre-pregnancy conditions/pregnancy complications (diabetes in pregnancy; pre-existing hypertension) reported in the initial descriptive analysis were not included in the adjusted models because they may be mediators of the association between maternal characteristics and GWG (our primary interest) and could introduce bias if included in the models. To determine whether the associations between obesity classes and GWG and GWG adequacy differed, the adjusted analysis was repeated but with BMI included in the models as a six-level variable (underweight, normal weight, overweight, obese class I, II, and III).

Though GWG differed between survey years, patterns of associations between GWG and maternal characteristics were similar regardless of survey year (data not shown) and we did not make inferences or conclusions about changes in GWG over time. Thus, for analyses of associations between maternal characteristics and GWG, data from the 2010 and 2016 surveys were combined and survey year was included in the models as a covariate rather than stratification variable. Due to the small amounts of missing data for covariates in the analytical sample $(<5 \%$ of women missing data for any covariate included in the multivariable analyses), multiple imputation was not conducted. Covariates with the highest percentages of missing data were: maternal pre-pregnancy BMI (1\%), employment during pregnancy $(1 \%)$, education $(1 \%)$, smoking status $(1 \%)$ and diabetes $(1 \%$; not included in multivariable models).

We used SAS software V.9.4 for Windows (SAS Institute) for statistical analyses.

\section{Patient and public involvement}

A network representing French user associations on questions related to pregnancy, childbirth and infancy was involved in the development of the questions on pregnancy and birth in the NPS and a website is maintained to disseminate results to participants and the wider public. However, there was no patient or public engagement for this research study.

\section{RESULTS}

In our nationally representative sample of French women, women's average GWG was $13.0 \mathrm{~kg}$ (SD 5.6; table 2), decreasing from $13.2 \mathrm{~kg}$ (SD 5.6) in 2010 to 12.7 $\mathrm{kg}$ (SD 5.7) in 2016 (online supplemental table 1). GWG decreased with increasing BMI, including across obesity classes. Only $37.0 \%$ of women attained adequate GWG, decreasing slightly from $37.7 \%$ in 2010 to $36.2 \%$ in 2016 . Excessive GWG was more common among women with overweight and obese BMI, while insufficient GWG was more common among women with underweight BMI. However, when examining obesity classes separately, excessive GWG decreased from obese class I to III, while insufficient GWG increased from obese class I to III.

In our cohort (table 3), almost $20 \%$ of women were born outside of France, a majority had normal weight BMI entering pregnancy, 30\% smoked either before or during pregnancy, $2.0 \%$ had pre-existing hypertension and $8.5 \%$ had diabetes in pregnancy. Compared with women excluded due to missing or implausible GWG, women included in our analytical sample were more likely to be primiparous, have a lower pre-pregnancy BMI, have modified their smoking habits during pregnancy and have characteristics indicative of higher socioeconomic status (online supplemental table 2).

In unadjusted analysis, clinically significant differences $(>1 \mathrm{~kg})$ in mean GWG were found for all maternal characteristics except maternal age and social deprivation (table 3), with higher GWG associated with characteristics indicative of higher socioeconomic status (maternal birth in France or Europe, higher education level, sufficient care) and reduced smoking in pregnancy. For pregnancy complications, mean GWG was lower among women with diabetes during pregnancy $(11.1 \mathrm{~kg}$, SD 6.5 among women with insulin controlled and $10.2 \mathrm{~kg}$, SD 7.0 among women with diet controlled diabetes compared to $13.2 \mathrm{~kg}$, SD 5.5 among women without diabetes during pregnancy) or pre-existing hypertension $(11.7 \mathrm{~kg}$, SD 
Table 2 Nationally representative estimates of GWG and GWG adequacy* in France (French National Perinatal Surveys 2010 and 2016; $\mathrm{N}=24850$ )

\begin{tabular}{llllll}
\hline & $\mathbf{n ~ ( \% )}$ & $\begin{array}{l}\text { GWG (kg) } \\
\text { mean (SD) }\end{array}$ & $\begin{array}{l}\text { Insufficient GWG } \\
\mathbf{n}(\%)\end{array}$ & $\begin{array}{l}\text { Adequate GWG } \\
\mathbf{n}(\%)\end{array}$ & $\begin{array}{l}\text { Excessive GWG } \\
\mathbf{n}(\%)\end{array}$ \\
\hline $\begin{array}{l}\text { Overall } \\
\text { BMI† }\end{array}$ & 24850 & $13.0(5.6)$ & $6606(26.8)$ & $9106(37.0)$ & $8892(36.1)$ \\
$\quad$ Underweight & $1960(8.0)$ & $13.9(4.8)$ & $762(38.9)$ & $785(40.1)$ & $411(21.0)$ \\
$\quad$ Normal weight & $15506(62.9)$ & $13.8(4.8)$ & $4473(28.9)$ & $6438(41.6)$ & $4574(29.5)$ \\
Overweight & $4545(18.4)$ & $12.2(6.0)$ & $687(15.1)$ & $1303(28.7)$ & $2552(56.2)$ \\
All obese & $2625(10.7)$ & $8.6(7.4)$ & $684(26.1)$ & $580(22.1)$ & $1355(51.7)$ \\
$\quad$ Obese class I & $1802(7.3)$ & $9.8(6.7)$ & $355(19.8)$ & $392(21.8)$ & $1050(58.4)$ \\
$\quad$ Obese class II & $589(2.4)$ & $7.0(7.7)$ & $201(34.2)$ & $138(23.5)$ & $249(42.3)$ \\
$\quad$ Obese class III & $234(0.9)$ & $3.6(8.3)$ & $128(54.7)$ & $50(21.4)$ & $56(23.9)$ \\
\hline
\end{tabular}

*Based on 2009 IOM thresholds, ${ }^{1}$ accounting for gestational age at birth ${ }^{38}{ }^{39}$; considered insufficient GWG if below recommendation, adequate if within recommendation or excessive if above recommendation.

†BMI $\left(\mathrm{kg} / \mathrm{m}^{2}\right.$ ): underweight, <18.5; normal weight, 18.5-24.9; overweight, 25-29.9; obese, $\geq 30$ (class I (30-34.9); class II (35-39.9); class III $(\geq 40))^{37}$

BMI, body mass index; GWG, gestational weight gain; IOM, Institute of Medicine.

7.3 compared to $13.0 \mathrm{~kg}$, SD 5.6 among women without pre-existing hypertension). In adjusted models, clinically significant differences in mean GWG persisted for maternal pre-pregnancy BMI, employment in pregnancy and smoking habits only.

In polytomous logistic regression models (table 4), underweight and obese BMI were positively associated with insufficient GWG. Additional characteristics positively associated with insufficient GWG included birth in sub-Saharan Africa, not being employed in pregnancy, less than high school education and insufficient prenatal care. Conversely, overweight BMI, stopping smoking and primiparity were inversely associated with insufficient GWG.

Overweight and obese pre-pregnancy BMI were positively associated with excessive GWG. Additional characteristics positively associated with excessive GWG included primiparity, not working or stopping work before 28 weeks' gestation, lower education level, and reduced or continued smoking. Conversely, underweight pre-pregnancy BMI was inversely associated with excessive GWG.

When adjusted analyses were repeated to evaluate obesity classes I-III separately (table 5), the trend of greater decreases in GWG compared with women with normal weight BMI persisted. Similarly, the odds of insufficient GWG increased across obesity classes, but the odds of excessive GWG decreased.

\section{DISCUSSION}

In France in 2010 and 2016, the majority of women did not achieve recommended GWG based on the 2009 IOM guidelines. Inadequate GWG was associated with underweight, overweight or obese pre-pregnancy BMI, smoking in pregnancy, primiparity and lower socioeconomic status. Differences in the prevalence of insufficient and excessive GWG were also noted by obesity class.

Though the majority of women in our study had inadequate GWG, our results (26.8\% insufficient, $36.1 \%$ excessive GWG) were similar to those found in recent multinational meta-analyses (LifeCycle (Europe, North America): $21.5 \%$ insufficient, $42.0 \%$ excessive $^{43}$; Goldstein et al (Europe, USA and Asia): $23 \%$ insufficient, $47 \%$ excessive). ${ }^{7}$ Examining GWG by BMI class, our findings (inverse relationship between pre-pregnancy BMI and mean GWG $^{143-47}$; positive association between insufficient GWG and underweight or obese BMI; positive association between excessive GWG and overweight or obese BMI $)^{15} 16203648-50$ were generally consistent with previous studies. Though inadequate GWG is more common among women with underweight, overweight or obese BMI, clinicians providing prenatal care should counsel all women regarding appropriate GWG for their prepregnancy BMI. Given the higher risk profile for adverse outcomes and the particular challenges to limit GWG for women entering pregnancy at higher BMI, providing information related to nutrition and physical activity for this group is particularly important. ${ }^{1}$ Additionally, as a recent systematic review found that midwives and obstetricians had insufficient knowledge of the IOM recommendations, ${ }^{51}$ educating clinicians on guidelines is also vital to ensure evidence-based prenatal counselling for appropriate GWG.

The average GWG (13.8 kg, SD 4.8) of women with normal weight BMI in our cohort exceeded the current French guidelines and mean GWG (with lower, ${ }^{30}$ higher $^{12}$ and similar estimates) ${ }^{31}$ and GWG adequacy (ie, insufficient, adequate or excessive GWG; with varying results depending on BMI category) ${ }^{12} 3032$ in the French population differed between studies. The differences between 
Table 3 Distribution of maternal characteristics in the sample and GWG associated with these characteristics (French National Perinatal Surveys 2010 and 2016)

\begin{tabular}{|c|c|c|c|}
\hline & n (\%) & $\begin{array}{l}\text { GWG (kg) } \\
\text { mean (SD) }\end{array}$ & $\begin{array}{l}\text { Adjusted* difference in GWG (kg) } \\
\text { difference }(95 \% \mathrm{Cl})\end{array}$ \\
\hline \multicolumn{4}{|l|}{ BMI† } \\
\hline Underweight & $1960(8.0)$ & $13.9(4.8)$ & $0.0(-0.3$ to 0.3$)$ \\
\hline Normal weight & 15506 (62.9) & $13.8(4.8)$ & Reference \\
\hline Overweight & 4545 (18.4) & $12.2(6.0)$ & $-1.6(-1.8$ to -1.4$)$ \\
\hline Obese & $2625(10.7)$ & $8.6(7.4)$ & $-5.1(-5.4$ to -4.8$)$ \\
\hline \multicolumn{4}{|l|}{ Parity } \\
\hline Multiparous & $14061(56.7)$ & $12.4(5.6)$ & Reference \\
\hline Primiparous & $10722(43.3)$ & $13.7(5.6)$ & 0.7 (0.5 to 0.8$)$ \\
\hline \multicolumn{4}{|l|}{ Age } \\
\hline$<25$ years & $3716(15.0)$ & $13.4(6.3)$ & $-0.0(-0.3$ to 0.2$)$ \\
\hline $25-29$ years & $8126(32.7)$ & $13.2(5.7)$ & Reference \\
\hline 30-34 years & 8079 (32.5) & $12.9(5.4)$ & $0.1(-0.1$ to 0.3$)$ \\
\hline$\geq 35$ years & $4918(19.8)$ & $12.5(5.5)$ & $-0.0(-0.3$ to 0.2$)$ \\
\hline \multicolumn{4}{|l|}{ Country or region of birth } \\
\hline France & 20398 (82.2) & $13.2(5.5)$ & Reference \\
\hline Europe & 957 (3.9) & $13.0(5.7)$ & $0.3(-0.1$ to 0.8$)$ \\
\hline Northern Africa & $1720(6.9)$ & $12.1(6.1)$ & $-0.2(-0.6$ to 0.2$)$ \\
\hline Sub-Saharan Africa & $1024(4.1)$ & $11.2(6.8)$ & $-0.6(-1.0$ to -0.1$)$ \\
\hline Other & $719(2.9)$ & $12.5(5.2)$ & $0.0(-0.5$ to 0.6$)$ \\
\hline \multicolumn{4}{|l|}{ Employment during pregnancy } \\
\hline None & $7089(28.7)$ & $12.3(6.4)$ & $0.1(-0.2$ to 0.3$)$ \\
\hline \multicolumn{4}{|l|}{ Stopped working during pregnancy } \\
\hline Before $14+0$ weeks' gestation & $1595(6.5)$ & $13.8(6.3)$ & $1.2(0.8$ to 1.5$)$ \\
\hline $14+0$ to $27+6$ weeks' gestation & $6701(27.1)$ & $13.5(5.5)$ & $0.6(0.4$ to 0.9$)$ \\
\hline $28+0$ to $31+6$ weeks' gestation & $4243(17.2)$ & $13.2(4.9)$ & $0.3(-0.0$ to 0.5$)$ \\
\hline Unknown stop point & $4743(19.2)$ & $12.8(5.6)$ & $0.1(-0.7$ to 0.9$)$ \\
\hline $\begin{array}{l}\text { Continued working to } \geq 32 \text { weeks' } \\
\text { gestation }\end{array}$ & $317(1.3)$ & $13.0(4.9)$ & Reference \\
\hline \multicolumn{4}{|l|}{ Education } \\
\hline Less than high school & $2158(8.7)$ & $11.9(6.8)$ & $0.6(0.2$ to 1.0$)$ \\
\hline High school & $9157(37.1)$ & $13.1(6.3)$ & $0.8(0.6$ to 1.1$)$ \\
\hline $1-2$ years postgraduation & $5086(20.6)$ & $13.2(5.3)$ & $0.6(0.4$ to 0.9$)$ \\
\hline $3-4$ years postgraduation & $4466(18.1)$ & $13.0(4.9)$ & $0.2(-0.1$ to 0.5$)$ \\
\hline$\geq 5$ years postgraduation & $3798(15.4)$ & $12.9(4.5)$ & Reference \\
\hline \multicolumn{4}{|l|}{ Social deprivation $\ddagger$} \\
\hline No & 20424 (82.2) & $13.1(5.4)$ & Reference \\
\hline Yes & $4414(17.8)$ & $12.5(6.6)$ & $-0.1(-0.3$ to 0.1$)$ \\
\hline \multicolumn{4}{|c|}{ Smoking habits before, during pregnancy } \\
\hline Non-smoker & $17216(69.9)$ & $12.4(5.3)$ & Reference \\
\hline \multicolumn{4}{|l|}{ Decreased smoking in pregnancy } \\
\hline$<10 \mathrm{cig} / \mathrm{d}$, stopped & $1855(7.5)$ & $14.4(5.3)$ & 1.5 (1.1 to 1.8$)$ \\
\hline$\geq 10 \mathrm{cig} / \mathrm{d}$, stopped & $1402(5.7)$ & $16.2(5.9)$ & 3.3 (2.9 to 3.7$)$ \\
\hline$\geq 10 \mathrm{cig} / \mathrm{d},<10 \mathrm{cig} / \mathrm{d}$ & $2185(8.9)$ & $14.0(6.2)$ & $1.3(0.9$ to 1.6$)$ \\
\hline
\end{tabular}


Table 3 Continued

\begin{tabular}{|c|c|c|c|}
\hline & n (\%) & $\begin{array}{l}\text { GWG (kg) } \\
\text { mean (SD) }\end{array}$ & $\begin{array}{l}\text { Adjusted* difference in GWG (kg) } \\
\text { difference }(95 \% \mathrm{Cl})\end{array}$ \\
\hline$<10 \mathrm{cig} / \mathrm{d},<10 \mathrm{cig} / \mathrm{d}$ & $845(3.4)$ & $13.4(6.4)$ & $0.9(0.4$ to 1.4$)$ \\
\hline Increased smoking in pregnancy§ & $47(0.2)$ & $13.6(5.4)$ & 1.1 (-0.9 to 3.2$)$ \\
\hline \multicolumn{4}{|l|}{ Insufficient careף } \\
\hline
\end{tabular}

Bold: clinically $(>1 \mathrm{~kg})$ and statistically significant mean difference.

*Estimated using adjusted linear regression models; adjusted on all covariates in table, survey year, GA at birth and mother's height.

†BMI $\left(\mathrm{kg} / \mathrm{m}^{2}\right)$ : underweight, <18.5; normal weight, 18.5-24.9; overweight, 25-29.9; obese, $\geq 30 .{ }^{37}$

¥Receipt of social benefits, not living in her own accommodation, not living with a partner

$\S$ Non-smoker, $<10 \mathrm{cig} / \mathrm{d}$; non-smoker, $\geq 10 \mathrm{cig} / \mathrm{d} ;<10 \mathrm{cig} / \mathrm{d}, \geq 10 \mathrm{cig} / \mathrm{d}$.

ILate pregnancy declaration (national health insurance not notified in first 3 completed months and no nuchal translucency measurement in first trimester) or insufficient sonograms ( $<2$ if GA at birth 24-33 weeks; $<3$ if GA at birth 34 weeks or later) or prenatal visits ( $<3$ if GA at birth 24-27 weeks; $<4$ if GA at birth 28-31 weeks; $<5$ if GA at birth 32-35 weeks; $<6$ if GA at birth 36 weeks or later), consistent with French guidelines for low-risk women.

BMI, body mass index; cig/d, cigarettes per day; GA, gestational age; GWG, gestational weight gain.

the French study results may be attributed to differences in study design (retrospective vs prospective; nationally representative vs limited/local hospital-based), location, GWG classification method (accounting for GA at birth or not), and inclusion/exclusion criteria (women with pre-existing conditions excluded or not). While our study is the first in France to provide nationally representative estimates of GWG and GWG adequacy, additional research within nationally representative samples of the French population is necessary to define adequate GWG in relation to adverse outcomes and clarify national guidelines.

Due to the lack of evidence to determine whether separate guidelines may be necessary in women with obese pre-pregnancy BMI, ${ }^{14}$ we extended our analyses to compare mean GWG and GWG adequacy between obesity classes. Our results are consistent with previous studies conducted in Europe, North America and Reunion Island, finding insufficient GWG increased and excessive GWG decreased from obesity class I to III $^{20} 5253$ and supporting evidence that lower GWG guidelines may be appropriate for higher obesity. ${ }^{4525455}$ Future research should address uncertainties regarding GWG guidelines for different obesity classes.

In line with previous research conducted in North America, Brazil, Australia, New Zealand and Ireland, we also found increased absolute GWG ${ }^{22} 2356$ and increased excessive GWG ${ }^{15} 202256$ among women who quit smoking in pregnancy, likely due to physiological changes to the metabolism and central nervous system resulting in increased appetite and the behavioural substitution of cigarettes with consumption of sugary foods. ${ }^{57}$ Given the obvious benefits of quitting smoking before or during pregnancy due to the adverse effects of smoking (eg, reduced fetal growth and birth size) ${ }^{58} 59$ smokers should be encouraged to reduce/stop smoking during pregnancy, be provided additional nutritional and psychological support to avoid adverse effects of excessive GWG, and be educated on the use of nicotine-replacement therapies (eg, nicotine patches).

Finally, we found that a number of maternal and social characteristics were associated with inadequate GWG, though consistency with prior literature was mixed. While we found increased GWG in primiparas compared with multiparas, a recent multinational systematic review concluded that the evidence is inconsistent and that the role of parity on GWG is likely indirect and complex. ${ }^{60}$ Overall, our results suggest that French women of lower socioeconomic status are more likely to have inadequate GWG, though the evidence for these factors is inconsistent. In contrast to our results, studies from Australia, New Zealand, Ireland, Brazil and the USA have found increased excessive GWG with younger maternal age. ${ }^{15} 194950$ Results for education have been mixed, with some previous studies from North American and Australia also finding lower education was associated with insufficient $/{ }^{517}{ }^{50}$ low $^{8}$ or excessive weight gain ${ }^{51749}$ but others from the USA and the Netherlands finding that the associations between education and GWG differed by maternal $\mathrm{BMI}^{20}{ }^{25}$ or no differences. ${ }^{18}$ Conflicting results have also been found related to immigration, with some previous research reporting higher GWG and increased excessive GWG in foreign nationals in Ireland ${ }^{27}$ or recent immigrants in Australia, New Zealand and Ireland ${ }^{15}$ but others finding insufficient GWG increased among foreignborn women in the USA ${ }^{16}$ or excessive GWG decreased among women of non-European ancestry living in the Netherlands, ${ }^{18}$ similar to our finding of increased insufficient GWG among women born in sub-Saharan Africa. In contrast, insufficient prenatal care was associated with insufficient GWG consistently across studies in the USA and Romania, ${ }^{162124}$ in line with our results. Given the 
Table 4 Associations between maternal characteristics and insufficient or excessive GWG* in multivariable logistic regression models (French National Perinatal Surveys 2010 and 2016; $\mathrm{N}=23931$ )

\begin{tabular}{|c|c|c|}
\hline & $\begin{array}{l}\text { Insufficient GWG } \\
\text { aOR† }(95 \% \mathrm{Cl})\end{array}$ & $\begin{array}{l}\text { Excessive GWG } \\
\text { aOR† }(95 \% \mathrm{Cl})\end{array}$ \\
\hline \multicolumn{3}{|l|}{ BMl‡ } \\
\hline Underweight & $1.4(1.2$ to 1.5$)$ & 0.7 (0.6 to 0.8$)$ \\
\hline Normal weight & Reference & Reference \\
\hline Overweight & $0.7(0.6$ to 0.8$)$ & 2.8 (2.6 to 3.1$)$ \\
\hline Obese & 1.5 (1.4 to 1.7$)$ & $3.3(2.9$ to 3.6$)$ \\
\hline $\begin{array}{l}\text { Primiparity (vs } \\
\text { multiparous) }\end{array}$ & $0.9(0.9$ to 1.0$)$ & 1.2 (1.2 to 1.3$)$ \\
\hline \multicolumn{3}{|l|}{ Age } \\
\hline$<25$ years & 1.1 (1.0 to 1.2$)$ & $1.0(0.9$ to 1.1$)$ \\
\hline 25-29years & Reference & Reference \\
\hline 30-34 years & $1.0(0.9$ to 1.1$)$ & $1.0(0.9$ to 1.1$)$ \\
\hline$\geq 35$ years & $1.0(0.9$ to 1.1$)$ & 0.9 (0.9 to 1.0$)$ \\
\hline \multicolumn{3}{|c|}{ Country or region of birth (vs France) } \\
\hline Europe & $0.9(0.8$ to 1.1$)$ & $1.1(0.9$ to 1.3$)$ \\
\hline Northern Africa & 1.1 (1.0 to 1.3$)$ & 1.1 (1.0 to 1.3$)$ \\
\hline Sub-Saharan Africa & $1.2(1.0$ to 1.5$)$ & 1.1 (0.9 to 1.3$)$ \\
\hline Other & 1.0 (0.8 to 1.2$)$ & 1.1 (0.9 to 1.3$)$ \\
\hline \multicolumn{3}{|c|}{ Employment during pregnancy } \\
\hline None & 1.2 (1.0 to 1.3$)$ & $1.2(1.1$ to 1.3$)$ \\
\hline \multicolumn{3}{|c|}{ Stopped working during pregnancy } \\
\hline $\begin{array}{l}\text { Before } 14+0 \text { weeks' } \\
\text { gestation }\end{array}$ & $1.0(0.8$ to 1.1$)$ & 1.6 (1.4 to 1.8$)$ \\
\hline $\begin{array}{l}14+0 \text { to } 27+6 \text { weeks' } \\
\text { gestation }\end{array}$ & 0.9 (0.8 to 1.0$)$ & $1.2(1.1$ to 1.4$)$ \\
\hline $\begin{array}{l}28+0 \text { to } 31+6 \text { weeks' } \\
\text { gestation }\end{array}$ & 0.9 (0.8 to 1.0$)$ & 1.1 (1.0 to 1.2$)$ \\
\hline Unknown stop point & $1.1(0.8$ to 1.4$)$ & $1.0(0.8$ to 1.4$)$ \\
\hline $\begin{array}{l}\text { Continued working to } \\
\geq 32 \text { weeks' gestation }\end{array}$ & Reference & Reference \\
\hline \multicolumn{3}{|c|}{ Education (vs $\geq 5$ years postgraduation) } \\
\hline Less than high school & $1.2(1.0$ to 1.4$)$ & 1.5 (1.3 to 1.7$)$ \\
\hline High school & $1.0(0.9$ to 1.1$)$ & $1.5(1.3$ to 1.6$)$ \\
\hline $\begin{array}{l}1-2 \text { years } \\
\text { postgraduation }\end{array}$ & 0.9 (0.8 to 1.0$)$ & 1.3 (1.2 to 1.5$)$ \\
\hline $\begin{array}{l}\text { 3-4 years } \\
\text { postgraduation }\end{array}$ & $1.0(0.9$ to 1.1$)$ & 1.1 (1.0 to 1.2$)$ \\
\hline Social deprivation§ & 1.1 (1.0 to 1.2$)$ & 1.0 (0.9 to 1.1$)$ \\
\hline \multicolumn{3}{|c|}{ Smoking habits before, during pregnancy (vs non-smokers) } \\
\hline \multicolumn{3}{|l|}{$\begin{array}{l}\text { Decreased smoking in } \\
\text { pregnancy }\end{array}$} \\
\hline$<10 \mathrm{cig} / \mathrm{d}$, stopped & 0.7 (0.6 to 0.8$)$ & 1.4 (1.3 to 1.6$)$ \\
\hline$\geq 10 \mathrm{cig} / \mathrm{d}$, stopped & $0.6(0.5$ to 0.7$)$ & $2.6(2.3$ to 2.9$)$ \\
\hline$\geq 10 \mathrm{cig} / \mathrm{d},<10 \mathrm{cig} / \mathrm{d}$ & 0.9 (0.8 to 1.0$)$ & 1.5 (1.4 to 1.7$)$ \\
\hline \multicolumn{3}{|c|}{ Maintained smoking level in pregnancy } \\
\hline$<10 \mathrm{cig} / \mathrm{d},<10 \mathrm{cig} / \mathrm{d}$ & 1.1 (0.9 to 1.3$)$ & 1.5 (1.3 to 1.8$)$ \\
\hline
\end{tabular}

Continued
Table 4 Continued

Insufficient GWG Excessive GWG aOR† $(95 \% \mathrm{Cl}) \quad$ aOR† $(95 \% \mathrm{Cl})$

$\geq 10 \mathrm{cig} / \mathrm{d},>10 \mathrm{cig} / \mathrm{d} \quad 1.2(1.0$ to 1.4$) \quad \mathbf{1 . 2}(\mathbf{1 . 0}$ to 1.4$)$

Increased smoking in

pregnancy

Insufficient care**

0.7 (0.3 to 1.5$)$

1.4 (0.7 to 2.7$)$

1.2 (1.1 to 1.4) $0.9(0.7$ to 1.0$)$

Bold: statistically significant association (does not cross null).

*Based on 2009 IOM thresholds, ${ }^{1}$ accounting for GA at birth ${ }^{38}$;9; considered insufficient GWG if below recommendation, adequate if within recommendation or excessive if above recommendation.

†Estimated using polytomous logistic regression models; adjusted on all covariates in table, survey year and mother's height.

‡BMI $\left(\mathrm{kg} / \mathrm{m}^{2}\right)$ : underweight, <18.5; normal weight, 18.5-24.9; overweight, 25-29.9; obese, $\geq 30$. $^{37}$

$\S$ Receipt of social benefits, not living in her own

accommodation, not living with a partner

IINon-smoker, $<10 \mathrm{cig} / \mathrm{d}$; non-smoker, $\geq 10 \mathrm{cig} / \mathrm{d}$; $<10 \mathrm{cig} / \mathrm{d}, \geq 10$ cig/d.

** Late pregnancy declaration (national health insurance not notified in first 3 completed months and no nuchal translucency measurement in first trimester) or insufficient sonograms ( $<2$ if GA at birth 24-33 weeks; $<3$ if GA at birth 34 weeks or later) or prenatal visits ( $<3$ if GA at birth $24-27$ weeks; $<4$ if GA at birth 28-31 weeks; $<5$ if GA at birth 32-35 weeks; $<6$ if GA at birth 36 weeks or later), consistent with French guidelines for low-risk women.

aOR, adjusted OR; BMI, body mass index; cig/d, cigarettes per day; GA, gestational age; GWG, gestational weight gain; IOM, Institute of Medicine.

disparate results across study settings, a deeper understanding of the underlying cultural context and social conditions is important to develop specific strategies to improve care for vulnerable populations and ensure all women, in particular those of lower socioeconomic status, can achieve a nutritionally adequate diet.

With its comprehensive analysis of factors contributing to GWG within a large, contemporary, nationally representative French cohort, our study builds on prior literature. As previous French GWG studies investigated different research questions, ${ }^{12}{ }^{30-32}$ we provide evidence of risk factors in a unique setting which could inform interventions locally and future research related to mechanisms underlying the observed associations. Additional strengths of our study include the extensive, rigorous data obtained in the NPSs by specially trained study personnel, which previous studies have confirmed are nationally representative based on comparisons of selected perinatal indicators (eg, maternal age, GA) available from birth certificate and hospital discharge statistics in the corresponding years. ${ }^{28}{ }^{29}$ By accounting for GA at birth in our definition of GWG adequacy and controlling for GA at birth in linear models of GWG, we limited potential biases due to the inherent correlation between GWG and length of gestation. ${ }^{61}{ }^{62}$ Additionally, our population included few preterm births (5.3\%) and preliminary sensitivity analyses of term pregnancies within our 
Table 5 Association between maternal pre-pregnancy BMI* and GWG and GWG adequacy, $\uparrow$ accounting for obesity classes I-III in adjusted regression models $\ddagger$ (French National Perinatal Surveys 2010 and 2016)

\begin{tabular}{|c|c|c|c|c|c|}
\hline & $\mathbf{N}$ & $\begin{array}{l}\text { GWG (kg) } \\
\text { mean (SD) }\end{array}$ & $\begin{array}{l}\text { Adjusted difference in GWG (kg) } \\
\text { difference }(95 \% \mathrm{Cl})\end{array}$ & $\begin{array}{l}\text { Insufficient GWG } \\
\text { aOR† }(95 \% \mathrm{Cl})\end{array}$ & $\begin{array}{l}\text { Excessive GWG } \\
\text { aOR† }(95 \% \mathrm{Cl})\end{array}$ \\
\hline Underweight & 1960 & $13.9(4.8)$ & $0.0(-0.3$ to 0.3$)$ & $1.4(1.2$ to 1.5$)$ & $0.7(0.6$ to 0.8$)$ \\
\hline Overweight & 4545 & $12.2(6.0)$ & $-1.6(-1.8$ to -1.4$)$ & 0.7 (0.6 to 0.8$)$ & 2.8 (2.6 to 3.1$)$ \\
\hline Obese class I & 1802 & $9.8(6.7)$ & $-3.9(-4.3$ to -3.6$)$ & $1.2(1.0$ to 1.4$)$ & 3.8 (3.4 to 4.3$)$ \\
\hline
\end{tabular}

BOLD: for adjusted differences, clinically $(>1 \mathrm{~kg})$ and statistically significant mean difference; for aORs, statistically significant association (does not cross null).

${ }^{*} \mathrm{BMI}\left(\mathrm{kg} / \mathrm{m}^{2}\right)$ : underweight, <18.5; normal weight, 18.5-24.9; overweight, 25-29.9; obese class I, 30-34.9; obese class II, 35-39.9; obese class III, $\geq 40$. $^{37}$

†Based on 2009 IOM thresholds, ${ }^{1}$ accounting for GA at birth ${ }^{38}{ }^{39}$; considered insufficient GWG if below recommendation, adequate if within recommendation or excessive if above recommendation.

łLinear regression used to estimated differences and polytomous logistic regression used to estimated aORs; adjustment variables: parity, maternal age, maternal country/region of birth, employment during pregnancy, education, social deprivation, smoking habits, insufficient care, survey year, mother's height (all models) and GA at birth (linear models only).

aOR, adjusted OR; BMI, body mass index; GA, gestational age; GWG, gestational weight gain; IOM, Institute of Medicine.

cohort were consistent with our main analyses (data not reported), providing further evidence that biases due to GA at birth were minimised. Additional methodological strengths are the large sample size and low level of missing data $(<5 \%$ in multivariable analyses).

Our study has some limitations. Measurement error is possible as some data were self-reported and collected retrospectively. Specifically, self-reported pre-pregnancy weight and maternal weight at birth may be biased due to underestimation. ${ }^{63}$ However, because reporting of weight gain during pregnancy in medical records is not standardised across France, the NPSs obtain this information through maternal self-report in order to have consistently collected and more complete data. While the resulting bias due to misclassification in measuring associations between GWG and adverse outcomes may be minimal, the impact of misclassification in examining risk factors for weight outcomes has not been evaluated. ${ }^{63}$ Only total GWG, not longitudinal GWG, was collected, reducing precision ${ }^{64}$ and not allowing us to examine variations in GWG trajectory across pregnancy or timing of GWG. GWG data in the NPSs used for our analysis were available for more than $90 \%$ of women and less than $5 \%$ of included women had missing data for covariates in our analysis. However, because differences were noted between included and excluded women, with excluded women being more likely to have characteristics indicative of lower socioeconomic status, we may have underestimated the association between these characteristics and GWG.

\section{CONCLUSIONS}

In France, a minority of women achieves the IOMrecommended GWG. Maternal pre-pregnancy BMI, continuing or quitting smoking in pregnancy, and lower socioeconomic status were associated with not achieving GWG recommendations. To promote adequate GWG and optimise pregnancy outcomes, clinicians should be trained to ensure all pregnant women receive evidencebased advice related to GWG and to provide additional support tailored to the specific needs of at-risk groups. Given the uncertainties regarding the current IOM GWG recommendations, additional research within nationally representative samples outside the USA and within BMI obesity classes is needed.

Acknowledgements The authors thank the Maternal and Child Health Service in each French district, the heads of the maternity units, the investigators and all the women who participated in the surveys.

Contributors $\mathrm{BB}$ and CLR contributed substantially to the design and data acquisition of the French National Perinatal Surveys. MH designed, and MA, CLR and JZ finalised the concept of the current study. MA conducted data analysis, interpreted the results and developed the draft manuscript under the supervision of $\mathrm{CLR}$ and $\mathrm{JZ}$, and with input from $\mathrm{BB}, \mathrm{KC}$ and $\mathrm{MH}$. All authors critically reviewed and approved the final manuscript.

Funding The 2010 and 2016 National Perinatal Surveys were supported by the French Ministry of Health (Direction de la Recherche, des Études, de l'Évaluation et des Statistiques (DREES), Direction Générale de la Santé (DGS) and Direction Générale de l'Organisation des Soins (DGOS); award/grant number N/A). The 2016 National Perinatal Survey was also supported by Santé Publique France (award/ grant number N/A). MA's postdoctoral fellowship is funded by the Inserm-NICHD agreement (award/grant number N/A).

Competing interests None declared.

Patient consent for publication Not required.

Ethics approval Each survey cycle was approved by the National Council on Statistical Information (Comité du Label; 2016 approval number 2016X703SA), the French Commission on Information Technology and Liberties (CNIL; 2016 registration number 915197), and the Inserm ethics committee (2016 approval IRB00003888 no. 14-191).

Provenance and peer review Not commissioned; externally peer reviewed. Data availability statement No data are available.

Supplemental material This content has been supplied by the author(s). It has not been vetted by BMJ Publishing Group Limited (BMJ) and may not have been 
peer-reviewed. Any opinions or recommendations discussed are solely those of the author(s) and are not endorsed by BMJ. BMJ disclaims all liability and responsibility arising from any reliance placed on the content. Where the content includes any translated material, BMJ does not warrant the accuracy and reliability of the translations (including but not limited to local regulations, clinical guidelines, terminology, drug names and drug dosages), and is not responsible for any error and/or omissions arising from translation and adaptation or otherwise.

Open access This is an open access article distributed in accordance with the Creative Commons Attribution Non Commercial (CC BY-NC 4.0) license, which permits others to distribute, remix, adapt, build upon this work non-commercially, and license their derivative works on different terms, provided the original work is properly cited, appropriate credit is given, any changes made indicated, and the use is non-commercial. See: http://creativecommons.org/licenses/by-nc/4.0/.

\section{ORCID iD}

Melissa Amyx http://orcid.org/0000-0003-4660-7716

\section{REFERENCES}

1 Institute of Medicine and National Research Council. Weight gain during pregnancy: reexamining the guidelines. Washington, DC: National Academies Press, 2010.

2 Abarca-Gómez L, Abdeen ZA, Hamid ZA, et al. Worldwide trends in body-mass index, underweight, overweight, and obesity from 1975 to 2016: a pooled analysis of 2416 population-based measurement studies in 128.9 million children, adolescents, and adults. The Lancet 2017;390:2627-42.

3 Diouf I, Charles MA, Blondel B, et al. Discordant time trends in maternal body size and offspring birthweight of term deliveries in France between 1972 and 2003: data from the French national perinatal surveys. Paediatr Perinat Epidemiol 2011;25:210-7.

4 Charles M-A, Eschwège E, Basdevant A. Monitoring the obesity epidemic in France: the Obepi surveys 1997-2006. Obesity 2008;16:2182-6.

5 Bouvier D, Forest J-C, Dion-Buteau E, et al. Association of maternal weight and gestational weight gain with maternal and neonate outcomes: a prospective cohort study. J Clin Med 2019;8:2074.

6 Morken N-H, Klungsøyr K, Magnus P, et al. Pre-pregnant body mass index, gestational weight gain and the risk of operative delivery. Acta Obstet Gynecol Scand 2013;92:809-15.

7 Goldstein RF, Abell SK, Ranasinha S, et al. Association of gestationa weight gain with maternal and infant outcomes: a systematic review and meta-analysis. JAMA 2017;317:2207-25.

8 Chu SY, Callaghan WM, Bish CL, et al. Gestational weight gain by body mass index among US women delivering live births, 20042005: fueling future obesity. Am J Obstet Gynecol 2009;200:271. e1-271.e7

9 Ashley-Martin J, Woolcott C. Gestational weight gain and postpartum weight retention in a cohort of nova Scotian women. Matern Child Health J 2014;18:1927-35.

10 Pugh SJ, Albert PS, Kim S, et al. Patterns of gestational weight gain and birthweight outcomes in the Eunice Kennedy Shriver National Institute of child health and human development fetal growth Studies-Singletons: a prospective study. Am J Obstet Gynecol 2017;217:346.e1-346.e11.

11 Hinkle SN, Sharma AJ, Swan DW, et al. Excess gestational weight gain is associated with child adiposity among mothers with normal and overweight prepregnancy weight status. J Nutr 2012;142:1851-8.

12 Jacota M, Forhan A, Saldanha-Gomes C, et al. Maternal weight prior and during pregnancy and offspring's BMI and adiposity at 5-6 years in the EDEN mother-child cohort. Pediatr Obes 2017;12:320-9.

13 Galjaard S, Pexsters A, Devlieger R, et al. The influence of weight gain patterns in pregnancy on fetal growth using cluster analysis in an obese and nonobese population. Obesity 2013;21:1416-22.

14 American College of Obstetricians and Gynecologists. ACOG Committee opinion no. 548: weight gain during pregnancy. Obstet Gynecol 2013;121:210-2.

15 Restall A, Taylor RS, Thompson JMD, et al. Risk factors for excessive gestational weight gain in a healthy, nulliparous cohort. J Obes 2014;2014:1-9.

16 Walker LO, Hoke MM, Brown A. Risk factors for excessive or inadequate gestational weight gain among Hispanic women in a U.S.-Mexico border state. Journal of Obstetric, Gynecologic \& Neonatal Nursing 2009;38:418-29.
17 Wells CS, Schwalberg R, Noonan G, et al. Factors influencing inadequate and excessive weight gain in pregnancy: Colorado, 20002002. Matern Child Health J 2006;10:55-62.

18 Gaillard R, Durmuș B, Hofman A, et al. Risk factors and outcomes of maternal obesity and excessive weight gain during pregnancy. Obesity 2013;21:1046-55.

19 Rodrigues PL, de Oliveira LC, Brito AdosS, et al. Determinant factors of insufficient and excessive gestational weight gain and maternalchild adverse outcomes. Nutrition 2010;26:617-23.

20 Deputy NP, Sharma AJ, Kim SY, et al. Prevalence and characteristics associated with gestational weight gain adequacy. Obstet Gynecol 2015;125:773-81.

21 Popa AD, Popescu RM, Botnariu GE. Adequate weight gain in pregnancy: an analysis of its determinants in a cross-sectional study. Srp Arh Celok Lek 2014;142:695-702.

22 Mongoven M, Dolan-Mullen P, Groff JY, et al. Weight gain associated with prenatal smoking cessation in white, non-Hispanic women. Am J Obstet Gynecol 1996;174:72-7.

23 Hulman A, Lutsiv O, Park CK, et al. Are women who quit smoking at high risk of excess weight gain throughout pregnancy? BMC Pregnancy Childbirth 2016;16:263.

24 Yeo S, Crandell JL, Jones-Vessey K. Adequacy of prenatal care and gestational weight gain. J Womens Health 2016;25:117-23.

25 Cohen AK, Kazi C, Headen I, et al. Educational attainment and gestational weight gain among U.S. mothers. Womens Health Issues 2016;26:460-7.

26 Paulino DSdeM, Peres GB, Peres GB, et al. Association between parity, pre-pregnancy body mass index and gestational weight gain. $J$ Matern Fetal Neonatal Med 2016;29:880-4.

27 Heery E, Kelleher CC, Wall PG, et al. Prediction of gestational weight gain - a biopsychosocial model. Public Health Nutr 2015;18:1488-98.

28 Coulm B, Bonnet C, Blondel B. French national perinatal survey 2016, 2017. Available: http://www.epopé-inserm.fr/en/grandesenquetes/enquetes-nationales-perinatales

29 Blondel B, Coulm B, Bonnet C, et al. Trends in perinatal health in metropolitan France from 1995 to 2016: results from the French national perinatal surveys. J Gynecol Obstet Hum Reprod 2017;46:701-13.

30 Cosson E, Cussac-Pillegand C, Benbara A, et al. Pregnancy adverse outcomes related to pregravid body mass index and gestational weight gain, according to the presence or not of gestational diabetes mellitus: a retrospective observational study. Diabetes Metab 2016;42:38-46.

31 Lecorguillé $M$, Jacota $M$, de Lauzon-Guillain B, et al. An association between maternal weight change in the year before pregnancy and infant birth weight: ELFE, a French national birth cohort study. PLoS Med 2019;16:e1002871.

32 Roussel E, Touleimat S, Ollivier L, et al. Birthweight and pregnancy outcomes in obese class II women with low weight gain: a retrospective study. PLoS One 2019;14:e0215833.

33 Deputy NP, Dub B, Sharma AJ. Prevalence and trends in prepregnancy normal weight - 48 States, New York City, and District of Columbia, 2011-2015. MMWR Morb Mortal Wkly Rep 2018;66:1402-7

34 Martin JA, Hamilton BE, Osterman MJK, et al. Births: final data for 2019. Nat/ Vital Stat Rep 2021;70:1-51.

35 Tandon A, Murray CJ, Lauer JA, et al. Measuring overall health system performance for 191 countries. Geneva: World Health Organization, 2000.

36 Haugen M, Brantsæter AL, Winkvist A, et al. Associations of pre-pregnancy body mass index and gestational weight gain with pregnancy outcome and postpartum weight retention: a prospective observational cohort study. BMC Pregnancy Childbirth 2014;14:1.

37 World Health Organization. Obesity: preventing and managing the global epidemic: report of a who consultation. Report No: 894. Geneva, Switzerland: WHO Technical Report Series, 2000

38 Bodnar LM, Siega-Riz AM, Simhan HN, et al. Severe obesity, gestational weight gain, and adverse birth outcomes. Am J Clin Nutr 2010;91:1642-8.

39 Liu J, Gallagher AE, Carta CM, et al. Racial differences in gestational weight gain and pregnancy-related hypertension. Ann Epidemiol 2014;24:441-7

40 Programme National Nutrition et Santé. Le guide de nutrition pendant et après La grossesse. Livret d'accompagnement destiné aux professionnels de santé. France: Agence française de sécurité sanitaire des aliments, 2007

41 Opatowski M, Blondel B, Khoshnood B, et al. New index of social deprivation during pregnancy: results from a national study in France. BMJ Open 2016;6:e009511.

42 Haute Autorité de Santé. Recommandations professionnelles. Suivi et orientation des femmes enceintes en fonction des situations 
Risque identifiées, 2007. Available: https://clinique.nc/wp-content/ uploads/2019/10/suivi_des_femmes_enceintes_-_recommandations 23-04-2008.pdf

43 LifeCycle Project-Maternal Obesity and Childhood Outcomes Study Group, Voerman E, Santos S, et al. Association of gestational weight gain with adverse maternal and infant outcomes. JAMA 2019;321:1702-15.

44 Nohr EA, Vaeth M, Baker JL, et al. Pregnancy outcomes related to gestational weight gain in women defined by their body mass index, parity, height, and smoking status. Am J Clin Nutr 2009;90:1288-94.

45 Santos S, Eekhout I, Voerman E, et al. Gestational weight gain charts for different body mass index groups for women in Europe, North America, and Oceania. BMC Med 2018;16:1-15.

46 Houde M, Dahdouh EM, Mongrain V, et al. The effect of adequate gestational weight gain among adolescents relative to adults of equivalent body mass index and the risk of preterm birth, cesarean delivery, and low birth weight. $J$ Pediatr Adolesc Gynecol 2015;28:502-7.

47 Faucher MA, Barger MK. Gestational weight gain in obese women by class of obesity and select maternal/newborn outcomes: a systematic review. Women Birth 2015;28:e70-9.

48 Chen A, Xu F, Xie C, et al. Gestational weight gain trend and population attributable risks of adverse fetal growth outcomes in Ohio. Paediatr Perinat Epidemiol 2015;29:346-50.

49 Al Mamun A, Mannan M, O'Callaghan MJ, et al. Association between gestational weight gain and postpartum diabetes: evidence from a community based large cohort study. PLOS One 2013;8:e75679.

50 Truong YN, Yee LM, Caughey AB, et al. Weight gain in pregnancy: does the Institute of medicine have it right? Am J Obstet Gynecol 2015;212:362.e1-362.e8.

51 Callaghan S, O'Brien E, Coughlan B, et al. Midwives' and obstetricians' level of knowledge of appropriate gestational weight gain recommendations for pregnancy: a systematic review. Birth 2020;47:322-31.

52 Hinkle SN, Sharma AJ, Dietz PM. Gestational weight gain in obese mothers and associations with fetal growth. Am J Clin Nutr 2010;92:644-51.
53 Bodnar LM, Pugh SJ, Lash TL, et al. Low gestational weight gain and risk of adverse perinatal outcomes in obese and severely obese women. Epidemiology 2016;27:894-902.

54 Robillard P-Y, Dekker G, Boukerrou M, et al. Relationship between pre-pregnancy maternal $\mathrm{BMI}$ and optimal weight gain in singleton pregnancies. Heliyon 2018;4:e00615.

55 Bogaerts A, Ameye L, Martens E, et al. Weight loss in obese pregnant women and risk for adverse perinatal outcomes. Obstet Gynecol 2015;125:566-75.

56 Favaretto AL, Duncan BB, Mengue SS, et al. Prenatal weight gain following smoking cessation. Eur J Obstet Gynecol Reprod Biol 2007;135:149-53.

57 Audrain-McGovern J, Benowitz NL. Cigarette smoking, nicotine, and body weight. Clin Pharmacol Ther 2011;90:164-8.

58 Hayes C, Kearney M, O'Carroll H, et al. Patterns of smoking behaviour in low-income pregnant women: a cohort study of differential effects on infant birth weight. Int J Environ Res Public Health 2016;13:1060.

59 Abraham M, Alramadhan S, Iniguez C, et al. A systematic review of maternal smoking during pregnancy and fetal measurements with meta-analysis. PLoS One 2017;12:e0170946.

60 Hill B, Bergmeier $\mathrm{H}$, McPhie S, et al. Is parity a risk factor for excessive weight gain during pregnancy and postpartum weight retention? A systematic review and meta-analysis. Obesity Reviews 2017;18:755-64.

61 Hutcheon JA, Bodnar LM. Good practices for observational studies of maternal weight and weight gain in pregnancy. Paediatr Perinat Epidemiol 2018;32:152-60.

62 Hinkle SN, Mitchell EM, Grantz KL, et al. Maternal weight gain during pregnancy: comparing methods to address bias due to length of gestation in epidemiological studies. Paediatr Perinat Epidemiol 2016;30:294-304.

63 Headen I, Cohen AK, Mujahid M, et al. The accuracy of selfreported pregnancy-related weight: a systematic review. Obes Rev 2017;18:350-69.

64 Mitchell EM, Hinkle SN, Schisterman EF. It's about time: a survival approach to gestational weight gain and preterm delivery. Epidemiology 2016;27:182-7. 